From the Anat. Labor. of Prof. H. SFTO, Tohoku University, Sendai.

\title{
Histological Studies on the Sensory Terminations Distributed in the Circulatory System and the Urogenital Organs.
}

\section{循環器及び尿性器に分布する知覚神経終末の組織学的研究}

\author{
Hachiro SETO 瀬 戸 八 郎.
}

[Received May 2, 1954.]

(The following treatise was lectured at the 59th General Meeting of the Japan Anatomical Association held on May 26, 1954.)

Throughout my twenty years of histological studies of the nerve system, the author has been most interested in the terminations of the peripheral sensory nerves. In this lecture, I will speak on the sensory terminations pertaining to the circulatory system and the urogenital organs in particular.

Formerly, sensory nerve terminations were too often confounded with vegetative nerve terminations, owing to the imperfection of the staining methods and the influence of LANGLEY's neuron theory, but since, in 1932, STÖHR aud REISER, and BOEKE established that the vegetative nerve termination is represented by the vegetative terminalreticulum through their utterly dependable researches, many succeeding studies have confirmed the truth of this finding, so that the study of sensory nerve terminations has been much facilitated, and the recent perfection of silver-staining methods has also contributed much in forwarding the histology of these terminations. Now, the author uses the term sensory nerve terminations in the meaning of the terminations of the peripheral medullated nerve fibres originating in the sensory nerve cells situated in the cerebrospinal ganglia. I can hardly concur with the theory postulating the existence of the so-called autonomous afferent nerve fibres.

\section{Distribution of sensory nerve fibres in the circulatory system.}

The distribution of sensory nerve fibres in the vascular system is rather limited in scope, being mainly found in the walls of the arteries but in few cases only in the walls of the veins. It is, however, of interest that sensory terminations are found also in arteriovenous anastomoses, and especially in the HOYER-GROSSER's organs. In the heart, the atria alone are provided with sensory fibres. In adults, the terminal 
formation is of course in a more completed state, but the distribution of sensory fibres is more limited, than in the embryonic stage. In the lymphatic system, no sensory termination has been proved in the lymph ducts, but some have been discovered in the lymph nodes.

In the vascular system, the following positions have been found to be provided with sensory terminations: the atria cordis; the arcus aortae and sinus carotici, which are the terminal places of the aortic and sinus nerves governing the blood pressure falling reflex (in embryos, extending to the aorta ascendens, the a. pulmonalis, the a. carotis communis and the a. anonyma); the small arteries pertaining to the heart paraganglia and the carotic glands; the aorta abdominalis; the aa. mesentericae; the aa. cerebrales; the HOYER-GROSSER's organs. Sensory nerve terminations are also not rarely found in the a. femoralis and the small blood vessels in the wall of the oviduct. It is of deep interest to find some special sensory terminations in the walls of the small veins in the atria cordis.

The sensory terminations in the atria cordis: The author has been the first to describe the existence of sensory nerve fibres and their terminations in human heart in 1936, and AIBA reported some new observations on them in 1953. A rather large quantity of sensory nerve fibres run into the human atria and form their terminations chiefly in the myocardium and endocardium thereof. The terminal formation may be classified into several types, as follows: 1 . The first type terminations (SUNDER-PLASSMANN) connected with the blood pressure falling reflex, as detailed hereunder. These are fonnd in the myocardium adjacent to the pericardium atrii in a limited quantity. 2. The ansiform terminations formed in the endocardium, to be subdivided into the simple and the complex subtypes. 3. Noncapsulated glomerular and ansiform terminations formed in or along the small nerve bundles running through the endocardium, rather rare in occurrence. 4. The sensory terminations formed in connection with the cardiac muscle fibres, also divisible into two subtypes; the spiral terminations encircling the muscle fibres in spirals and the indefinite branched terminations widely diffused among the muscle fibres. 5. The peculiar branched terminations entwining the minute veins rnnning through the musclular layer. Such a variety of sensory terminations are found in the atria cordis of man in a large quantity.

The atria cordis of mammals are also provided with a rather large number of sensory terminations but their structure is far simpler than in the human heart. For example, only simply formed terminations type 1 pertaining to the blood pressure falling reflex, simplest unbranched terminations and simple branched terminations with a few rami are 
found in the atria cordis in dog (SATO, 1954).

Sensory terminations connected with the blood pressure falling reflex: Through the well-known physiological experiment by HERING in 1924, it became known that the so-called $n$. depressor is afferent in nature and that the sinus nerve distributed in the carotic sinus discovered by him was one of such nerves. Several years afterwards, de CASTRO (1928) and SUNDER-PLASSMANN (1930) made histological studies of the terminations of the adult human sinus nerve and affirmed that these were represented by very peculiarly formed terminal apparatus. Their observations were later on confirmed by STÖHR and more recently further. illumination was thrown on the structure of these terminations by the stndies of MEIJLING (1938) and OHTOMO (1948).

The terminations of the aortic nerve distributed in the arcus aortae were described in the reports by TELLO (1924), TSCHERNJACHIWSKY (1930), PALME (1934), MURATORI (1935) and NONIDEZ (1935), but since all these studies were concerned with human and mammalian embryos, the terminations were described as of very simple structure, unlike those of the adult human sinus nerve. The author has the honor of being the first in describing in detail the terminations in this part with adult human specimens as material (1937). In fact, sensory terminations similar to those found by SUNDER-PLASSMANN (1930) in the carotic sinus were found in the arcus, especially at its caudal edge, in a much larger quantity.

These terminations connected with the blood pressure falling reflex in human adults are formed in the terminal territory of connective tissue belonging to the adventitia projecting into the media and can be subdivided into two kinds. The one is represented by complex branched terminations with occasional fibril terminal plates of very peculiar formation and the other by complex arborized terminations mostly accompanying small arteries.

SUNDER-PLASSMANN (1933) has discovered terminations of the first type also in the mucosal muscle layer of the adult human pulmonary bronchial rami. SASAKI (1943) and MATSUMOTO (1950) reported existence of conspicuous terminations type I and II in the mucous membranes of the larynx and the trachea. The author, as mentioned above, has found those of type $I$ in the adult human atria, though in a small quantity. Thus it has been discovered that the sensory terminations connected with the blood pressure falling reflex are found not only in the carotic sinus and the arcus aortae, but also in the atria cordis as well as the respiratory tract, in particular, in the larynx, the trachea, the bronchi and their branches.

It is of great interest that the distribution of the sensory fibres 
connected with the blood pressure falling reflex is much wider in scope in human embryos than in adults and their terminal formation also differs much in the two stages. According to a study by YABUKI (1953), the aortic nerve in an embryo, with its center at the inferior edge of the arcus aortae, distributes in the entire wall of the arcus, the aorta ascendens; the a. anonyma and a. carotis communis sinistra at their proximal parts and even the pulmonary artery. The terminations are very markedly developed in the earlier stage of the embryonic life, but gradually fall into degeneration in the latter.

The terminal formation of the numerou sensory fibres distributed in the arcus aortae and the aorta ascendens of a human embryo is quite different from that of human adults, no double-typed classification being ever possible. Here, stout sensory fibres run into the media through the adventitia, ramify alongside the annular muscle fibres of the media and pass over into arborized or indefinite branched terminations. The terminal branches frequently show change in size and of ten corpuscle formation by neurofibril distension in the course. Next, at the proximal parts of the a. anonyma and carotis communis sinistra, some sensory terminations similar to the foregoing are also found, which sometimes extend into the intima. The same may be said of the pulmonary arteries, the terminations found only at the most proximal parts thereof, becoming extremely rare at the more peripheral parts.

The sensory terminations of the aortic nerve are best developed as beautiful arborized forms in embryos of the four and five months, but gradually degenerate in embryos more than six months old. In an eighth month embryo, few terminations are found in the media, only some simple branched terminations being observable in the adventitia adjoining the media. Such a degeneration is especially notable in the pulmonary arteries.

Thus, it is of no small interest that the peculiarly shaped sensory terminations that, in embryonic stage, are formed in the media as well as the intima, utterly disappear post-natally, terminations of this kind surviving only in the arcus aortae, in utterly different forms of two varieties. Now, the mode of the consolidation of the terminations in the arcus may be, I believe, looked upon as something similar to the postnatal change of the sensory nerve distribution in the head of penis or clitoris, as detailed hereunder, where the intraepithelial sensory fibres, which run into the common epithelium covering both the glans penis or clitoridis and the inner plate of the praeputium, completely degenerate after birth, to give way to the very complex genital nerve bodies formed beneath the epithelium.

The fact that the sinus nerve is much more widely distributed in 
embryos than post-natally, as was the case with the aortic nerve, is evidenced by the existence of branched sensory terminations found penetrating into the media, and even at times into the intima, of the upper common carotis artery and the roots of the aa. carotis interna et externa in embryos of middle stage.

Such a wider distribution of sensory nerve fibres regulating the blood pressure falling reflex in embryos and the consequent formation of their terminations deep in the media and intima of the arteries clearly indicates that, physiologically speaking, the blood circulation in the embryos requires a much more delicate adjustment of blood pressure than in adults.

Sensory nerve fibres are also found in the walls of the small arteries running into the heart paraganglia and the carotic glands. These are of rather simple branched formation. The above glands are both nonchromaffine paraganglia and are believed to be endocrine organs connected with the blood pressure falling reflex. So, it is no wonder that sensory terminations resembling the terminations type II connected with such a reflex are found in them, and it is beyond doubt that a reflex are for reducing blood pressure is found here too.

It has been long known that sensory terminations are found the abdominal aorta, and many of them are found especially along the aorta running through the abdominal wall dorsal to the duodenum and the caput pancreatis. It is of special interest that these terminations are nearly all PACINIAN bodies. STÖHR (1928) presumed them to be reflex origins for blood pressure adjustment. Maybe they are concerned with blood pressure rise, since they are situated at the level of the suprarenal glands. HIRSCH (1926) has reported on capsulated glomerular terminations surrounding the femoral artery, but these are apparently of very rare occurrence, if any.

A ratner large quantity of terminations, manifold in shape but especially predominant in glomerules, is found in the cerebral pia mater, aud also some in the walls of the blood vessels running in the pia (STÖHR 1922). The author has also observed comparatively simple branched terminations at many points along the walls of the small arteries penetrating the cerebral substance. These terminations in the vascular walls are also presumably receptors for change in blood flow, and in pathological cases, are responsible for heac'-aches.

It is also of interest that numerous sensory fibres ending in branched terminations are found running through the media into the epitheloid tissue around the intima of the HOYER-GROSSER's organs existing in the palms and the soles. If it is true that these organs are of endocrine nature secreting acethylcholine-like substance from their 
epitheloid cells, like the non-chromaffine paraganglia, they must cause reflex blood pressure fall according as the blood flow changes.

Beside the above, extremely small numbers of sensory terminations have been proved to exist, in the vascular system, in the small vessels in the oviduct and the small arteries of the mesenterium. The terminal formation here is always represented by branched terminations.

No sensory termination has been discovered along the lymphducts, but in the lymph nodes a small quantity of simple branched terminations have been observed. Existence of such terminations is especially marked in the lymph nodes in the mesenterium and the dorsal abdominal wall. PACINIAN bodies are often found formed in the lymph nodes in the vicinity of the head of the pancreas.

\section{Sensory terminations distributed in the urogenital organs.}

No sensory nerve fibres have been proved in the kidney, nor any sensory termination has been reported as found in the pelvis renalis and the ureter. But as some thick medullated fibres are seen running in the kidney, there is a possibility of some terminations formed therein. Only in the lowest parts of the ureter the existence of sensory fibres running into the tunica mucosa through the muscularis and their terminations has been positively proved.

A rather large number of sensory fibres is found distributed in the mucous membrane of adult human bladder (YOKOYAMA 1949). Most of these fibres are found in the papillary formations among the crypts in the trigonum resicae, especially abundant along the isosceles sides of the triangle. They are proved in evidence also around the orifices of the ureteres and the orificium internum urethrae. Their terminations comprise the four types of unbranched, branched, glomerular and intraepithelial forms. The branched terminations are either simple or complex, the latter comprising arborized and indefinite types. The glomerular terminations are either capsulated or not, contain numerous special nuclei and resemble the genital nerve bodies type I, though much poorer in size and structure than the latter.

The intraepithelial fibres observed in the transitional epithelium of the bladder run between or through the epithelial cells, as other intraepithelial fibres in general. This fact seems to make us suspect the absence of any solid cell membrane covering the cells, because a solid membrane would considerably hinder the transition of nerve fibres. Such transitional intraepithelial fibres may originate in terminations of any type formed in the propria described above, are either branched or unbranched themselves, and end in sharp points or small button-forms. 
The terminal formation of the sensory fibres found in the mucous membrane of the lower parts of the ureter is similar to that of the nerve fibres in the bladder, but the fibres and their terminations are much poorer in quantity and development here than in the bladder.

Dogs and cats are also known to have sensory fibres in their bladders, but the number of fibres is far smaller and the terminal formation much simpler than in human bladder.

The bladder of a human embryo is likewise provided with numerous sensory nerve fibres, but their terminations are extremely simply formed, no such complex types as the glomerular terminations ever being found in embryonic bladders (IWASAKI 1951 and OIKAWA 1954).

The urethra of human male is rich in sensory nerve fibres (SETO 1939 and NOBUTA 1949), gaining in quantity as we go forward from the inner orifice, and their terminations become more and more complex. The terminations comprise branched and glomerular types formed in the lamina propria, of which the latter type belongs in most cases to the first type of the capsulated small-sized genital nerve bodies. Intraepithelial fibres are also found in many parts of the urethral epithelium. These are mainly represented by complex branched terminations in the pars cavernosa urethrae, but by simple-typed terminations in the pars prostatica urethrae. Besides, intraepithelial fibres are also found in the double columnar epithelium of the ducts of the urethral glands, sometimes even as stout fibres ending in complex branched terminations. In the stratified flat epithelium of fossa navicularis urethrae, however, there have been found no intraepithelial fibres. The sensory terminations are found in remarkable development in the urethra of a male embryo in its latter stage, but then the terminations formed in the propria are either unbranched or simple branched endings, no corpusculär termination being formed as yet. In a seventh month embryo, the intraepithelial fibres are still unbranched, but in a tenth month embryo, they are occasionally found as ramified into two or three branches.

Thus, we see that there are rather numerous sensory terminations existing in the mucous membrane of the urethra of human male, so that it is nothing unnatural that excruciating pain is felt in the case of urethritis etc.

Of the male genital organs, the testicle (YAMASHITA 1939) is provided with a rather large number of sensory nerve fibres which form terminations upon reaching the subperitoneal tissue of the tunica albuginea. Their terminal formation is represented by unbranched and simple branched terminations, but none of these penetrates into the epithelium. These terminations seemingly respond to external pressure affecting the testicles and are designed to act as a protective device for the testicles. 
No sensory fibre is proved in the parenchyma of testicle. In the rete testis, not only do some sensory fibres end in simple branched terminations in the periphery of the rete, but also some are found to penetrate into its single-rowed epithelium to pass over into intraepithelial fibres.

KAWAHARA reports observation of sensory nerve fibres in the epididymis, but the author and his collaborators have not yet succeeded in endorsing the observation. Sensory terminations are found in many pars of the ductus deferens (YAMASHITA 1939), the ampulla being especially rich in well-formed terminations. Here, the sensory nerve fibres pass through the tunica muscularis in company with vegetative nerve fibres into the propria to end beneath the epithelium, especially frequently in the papillary formations, in branched or corpuscular terminations. The latter are generally glomerular in type, the capsulated ones giving the appearance resembling the genital nerve bodies type I. Intraepithelial fibres are also frequently observed, always ending in simple branched terminations, resembling in form those found in the urethra but poorer in general development. The significance of these sensory terminations may possibly lie, as in the case of those in the rete, in their capacity to feel the passage of semen, and reflexly expediting the functions of the gonads and other internal genital organs. An extremely small quantity of sensory nerve fibres and their simple-typed terminations is found also in the vesicula seminalis.

A large number of sensory nerve fibres and their terminations of many forms is found in the prostata. It is of special interest that a particularly large quantity of them is found in the striated muscle layer around the anterior lobe and in the smooth muscle layer and connective tissue layer on its inner and outer sides. The unbranched terminations, relatively small in number, are formed by thick fibres generally showing change of size in their course and ending in various shapes. The second branched terminations are more abundant and mav be divided into the simple and the complex subtypes. The simple subtype is represented by well-defined branched endings diffusing widely through their few rami, which show marked change of size and winding. The complex subtype terminations are not so much diffused, but the rami are more numerous and their change in size and winding are much more accentuated, so that their general arrangement looks bush-like. Their terminal area contains numerous special nuclei. The third spherical corpuscular terminations are represented by neurofibril globular bodies formed in the terminal rami, but these are not frequently encountered. The fourth glomerular terminations are also rather scarce. They are formed by a small number of trunk fibres forming glomerular arrangement by frequent ramification and anastomosis, containing many special nuclei, but generally devoid 
of any connective capsule.

Very few sensory nerve fibres are found running into the parenchyma of the Jateral lobe of the prostata, but the parenchyma of the anterior lobe, especially its peripheral parts, is rich in sensory nerve fibres coming in from the striated muscle layer, the terminations of which are similar to those described above in formation, but poorer in development, so that no termination belonging to the more complex type are seen here. The terminal branches of ten run close along the gland cells, but never into the cells.

The ductus ejaculatorius is provided with sensory fibres in some extent. Their terminations are simple branched endings located subepithelially. No intraepithelial fibre has been found in the single columnar epithelium at the root of the duct; but some simple intraepithelial fibres are found in the double columnar epithelium near the orifice into the urethra. The development of sensory fibres in the utriculus porstaticus is very poor, only some fibres being found running through the subepithelial tissue on rare occasions.

It has been known of old that the penis is rich in sensory nerves, but their mode of termination and distribution, however, has been left in the dark in many points. Our studies have revealed that there are numerous sensory terminations found in the penis, comparable to those in the clitoris. For the fine structure of the sensory fibres and their terminations, reference is made to their description in the chapters on the clitoris and the labium minus pudendi.

The small PACINIAN bodies found in this part are formed in a comparatively small number along the course of the branches of the $n$. dorsalis penis. The genital nerve bodies concerned with the sexual sensation are divisible into the three types I, II and III. The bodies types I and II are most abundant in the glans penis, but some are also found in the papillary layer of the praeputium. Bodies type III are formed in the tunica albuginea of corpus cavernosum penis, especially between its two connective tissue layers. Unbranched and branched terminations are also found here and there, most frequently beneath the epithelium of the glans penis and next in the papillary layer of the praeputium.

In speaking on the sensory innervation of the penis and the clitoris, we must not pass over the intraepithelial fibres existing only in embryos. As we can see in a cross-section of the glans penis aut clitoridis of an embryo, there is found a common epithelium between the glans and the inner plate of the praeputium, which is rich in protuberances and depressions on both sides and showing the shape of a rosary in crosssection. Sensory fibres that have lost their myelin run into this common epithelium to end there in very peculiar shaped terminations, These 
intraepithelial fibres are at the peak of development in a seventh month embryo, but thereafter, according as the epithelium begins to part at the tip of the glans, these fibres begin to degenerate, so that in a tenth month embryo the number of such fibres is greatly diminished, and after birth, when the partition of the epithelium is completed, the intraepithelial fibres also disappear altogether. The genital nerve bodies, which are yet unformed in the embryonic stage, seem gradually to be formed from the thick trunk fibres of such degenerated intraeplthelial fibres.

The terminations of such intraepithelial fibres typically developed in a seventh month embryo may be divided into two types. The one is formed by minute fibres, which run a peculiar ansiform course without showing much change of size and spread out widely together with many branches to end in a kind of complex branched terminations. The other is found in the globular formations of aggregated epithelial cells and represented by simple branched terminations, the terminal fibres in which frequently show evident change in their size. Both the terminations are developed more in complexity in the glans penis than in the glans clitoridis, because the development of the common epithelium is in the former much stronger than in the latter. The common epithelium is in formation nowhere in the glans penis of adult male, while in the glans clitoridis of adults it is still observable at the root of the glans, but no intraepithelial fibre is found running therein.

The scrotum and the perineum are peculiar in nature of all haired skin. Especially, the well-developed papilla formation into the epidermis suggests the high abundance in sensory nerve fibres, in comparison with the skins in other parts which are generally poor in such papillae. In fact, the scrotum and the perineum are found to be rather richly provided with sensory nerve fibres, which have characteristic end formations. Quite as in the glans and the praeputium, genital nerve bodies types I and II are formed, though in a lesser number, in the papillary layers. especially in the papillae, of the scrotum and the perineum. What is of interest is that such bodies are found distributed also in the cutaneous and the intermediary parts of the anus.

Beside the genital nerve bodies, unbranched and simple branched terminations are found in a comparatively large number, and also some uncapsulated glomerular and plexus-like terminations, in the papillary layer of the scrotum and perinenm. The sensory hair nerve fibres to the hair follicle necks of the pubes have generally their terminal areas in the shape of the author's so-called hair nerve shields, so that their terminations are of comparatively simple plexus type, somewhat, however, more complex than those found by the capilli.

The scrotum, the perineum and the anus are covered by the charac- 
teristic skin belonging to the external genitals, as far as their tissue structure and sensory innervation are concerned, but also the papilla and areola mammae, not only of women, but also of men (SUGA 1951), show the same nature of skin, since the papillae into the epidermis are conspicuously formed and smooth muscles are present, and also sensory nerve fibres are richly provided, with characteristic terminal formation, including some genital nerve bodies, though in a small number. Smallsized PACINIAN bodies are found in a small number in the papilla mammae, but not in the scrotum and the perineum.

In the female genital organs, medullated fibres are found penetrating even into the ovarium (SAKAGUCHI 1939). Their terminations are formed in the medullar substance and the cortical substance adjoining it, by sensory fibres that have lost their myelin, spread out considerably widely in several branches and forming indefinite terminations arranged very irregularly. The branches run winding courses while showing peculiar change in size and then end sharply, bluntly or in small nodules. Since sensory nerve fibres are also found in the mesovarium, it is probable that sensory terminations are formed therein, too.

Sensory nerve fibres run into the oviduct also, forming their terminations of simple branched type in the walls of the small blood vessels in the tunica subserosa, though in a very small quantity (SAKAGUCHI 1939). Besides, RIES and CARYLLES have reported on PACINIAN bodies and HARTING on MEISSNER's tactile bodies in this part, but these are presumably of very rare occurrence.

Some researchers have stated that some medullated fibres run into the uterus of human adults, but the existence of sensory nerve terminations has not yet been proved to date. OIKAWA (1954) and NISHIMURA (1954) of this laboratory have studied the wombs of fourth month and fifth and sixth month embryos respectively and found that thick afferent fibres, readily distinguishable from the vegetative nerve fibres run into the uteri, to end unbranched or branched in simple forms in the propria therein. The distribution of these fibres was densest at the cervix, followed by the corpus and the fundus, being almost absent in the portio vaginalis. The sensory innervation of human adult uterus is now under research at this laboratory.

Sensory nerve fibres in the vaginal wall (IKUI 1949) are very poor in development, and some simply formed sensory terminations are found only at the outer orifice. But once the vestibulum vaginae is reached, the sensory nerve fibres suddenly rise in number (IKUI 1949). The terminations of these fibres are in most cases formed in the well-developed papillae and are unbranched, simple branched or sometimes arborized in form. Corpuscular terminations, however, are not found. 
The labium minus pudendi (IKUT 1949) is even richer than the vestibulum vaginae in sensory nerve fibres. The development of the terminations is higher in the inner plate, where the papillae are also better developed, than in the outer plate. The types of the terminations comprise unbranched, simple branched, plexus-like and genital nerve body types, which are always formed in the papillae.

The genital nerve bodies in the labium minus are classified into types I and II. The former is composed of a glomerular termination distributed densely in the entire area of the inner bulb, while the latter of a branched termination, the nerve fibres of which are loosely arranged in the middle of the inner bulb. Terminations of both types are always capsulated and the their inner bulb consists of minute granular hard-tostain ground substance and numerous special nuclei, is syncytic without intercellular boundaries and is a continuation of the SCHWANN's sheath that encircles the trunk fibre, so that the special nuclei are derived from SCHWANN's nuclei. The genital nerve bodies in this part are generally somewhat smaller than those in the glans clitoridis.

As for the sensory innervation of the glans clitoridis (YAMADA 1951), embryologically speaking, it is very rich in sensory fibres already in the latter stage of the embryonic life, though the terminations are still of very simple description, consisting of unbranched and simple branched types only, genital nerve bodies being as yet unformed. Smallsized PACINIAN bodies are, however, already well-developed. As the PACINIAN bodies are formed along the course of the $\mathrm{n}$. dorsalis clitoridis, their distribution is very distinctly observed in the small clotoris of an embryo. A small number of them is formed at the root of the $n$. dorsalis clitoridis, and they increase in number as we go forward, becoming most abundant at the fore half of the corpus cavernosum clitoridis, but decrease sharply in the topmost part of the cavernous body. A small number of small-sized bodies are also found along the branches of the dorsal nerve running into the praeputium. The other simpler PACINIAN bodies are formed in the propria of the glans and the subepithelial tissue of the praeputium, and not rarely also on the periphery of the corpus cavernosum clitoridis. Some special intraepithelial fibres are found in the common epithelium over the glans and the inner plate of the praeputium, as has been described above in connection with the penis.

The development of sensory terminations reaches the maximum in the clitoris of adults, the density of distribution ranging in the order of the glans, inner plate of the praeputium and its outer plate. The density of distribution in general in the clitoris is far higher than in the masucline glans penis. The terminations here comprise branched types of every stage of complexity and numerous genital nerve bodies, 
while PACINIAN bodies also come into extraordinary development here, with about a score of lamellae and an inner bulb containing a branched type of sensory termination in general.

Beside the above types I and II of the genital nerve bodies (IKUI 1949), there is also a distinct type III thereof (YAMADA 1951). The terminations type $\mathrm{I}$ are most abundant in the propria of the glans, followed by the inner and then the outer plate of the praeputium and are not rarely found in the corpus cavernosum glandis too. Those of type II are also most abundant in the propria of the glans, next in the inner plate of the praeputium, the corpus cavernosum glandis, especially in its peripheral parts, the outer plate of the praeputium and in the peripheral parts of the corpus cavernosum clitoridis, in the order named. This type show a tendency to group formation, as in the penis. Types I and II can be divided into capsulated and uncapsulated subtypes. The type III terminations are found only in the tunica albuginea of the corpus cavernosum clitoridis or the girder tissue of the corpus cavernosum glandis, which are of tough connective tissue in substance. As these terminations are always uncapsulated and their inner bulbs are not of definite form, they are represented by complex branched endings accompanying numerous special nuclei, and in very many cases end in arborized form. Since, however, these terminations show similarity to those of uncapsulated type II in substance, these must be also looked upon as belonging to the genital nerve bodies.

\section{References.}

Aiba: Arch. hist. jap. 6 (1954). P. 213. - de Castro: Trav. Lab. Rech. Biol. Madrid. 25 (1928). P. 331. - Hermann: Z. Anat. 114 (1950). S. 685. - Hirsch: Arch. Klin. Chir. 137 (1925). S. 281. - Hotta: Arch. hist. jap. 4 (1952). P. 1. - Ikui : Tohoku Igaku Zassi (Jap.) 39 (1949). P. 105 \& 112. - Iwasaki : ibid. 46 (1951). P. 98. - Matsumoto: ibid. 45 (1950). P. 11 - Meijling: Acta neerl. morph. normal. path. 1 (1938). P. 193. Muratori: Arch. ital. anat. embr. 34 (1934). P. 421. - Nishimura: Arch. hist. jap. 6 (1954). P. 233. - Nobuta: Tohoku Igaku Zassi. (Jap.) 39 (1949). P. 5 a. 15. - Nonidez: Anat. Rec. 62 (1935). P. 47. - Ontomo: Tohoku Igaku Zassi. (Jap.) 39 (1948). P. 39. - Oikawa: In press. Tohoku J. exp. Med. - Palme: Z. mikr. -anat. Forsch. 36 (11934). S. 391. - Sakaguchi : J. orient. Med. (Jap.) 30 (1939). P. 795 a. 827. - Sakuraoka: In press. Arch. hist. jap. - Sasaki : Tohoku Igaku Zassi. (Jap.) 32 (1943). P. 569. Sato: Tohoku J. exp. Med. 59 (1954). P. 343. - Seto: Arb. Anat. Inst. Sendai. 19 (1936). S. 1. - ibid. 20 (1937). S. 1. - ibid. 22 (1939). S. 1. Advance of Medicine. (Jap.) 5 (1948). P. 225. - Stöhr: Z. Anat. 63 (1922). S. 555 u. 562 . - Mikr. Anat. d. vegetat. Nervensystems. J. Springer, Berlin, 
1928, - Erg. Anat. 32 (1938). S. 1. - Z. Zellforsch. 30 (1939). S. 78. Suga: Tohoku Igaku Zassi. (Jap.) 45 (1951). P. 327. - Sunder-Plassmann : Z. Anat. 93 (1930). S. 567. - Z. Neur. 147 (1933). S. 414. - Tello: Trav. Labor. Rech. Biol. Madrid. 22 (1924). P. 295. - Tschernjachiwsky : ibid. 26 (1929-30). P. 75. - Yabuki : Tohoku J. exp. Med. 57 (1953). P. 145. Yamada: ibid. 54 (1951). P. 156 \& 163. - Yamashita: J. orient. Med. (Jap) 30 (1939). P. 367 a. 395. - Yokoyama: Tohoku Igaku Zassi. (Jap.) 42 (1549). P. 28. 